\title{
Pollutant toxic ions and molecules. A global pollution problem: trends in detection and protection
}

\author{
Carlos Lodeiro $^{1,2}$ - Jose Luis Capelo ${ }^{1,2} \cdot$ Elisabete Oliveira $^{1,2} \cdot$ Cristina Nuñez $^{1,3}$
}

Received: 23 March 2016 / Accepted: 11 April 2016/Published online: 21 April 2016

(C) Springer-Verlag Berlin Heidelberg 2016

How long is it going to take humans to realise they are poisoning till death the only planet they know that can sustain life?

That the planet is dying is well known by politics, by those who should take action.

Why action is not taken is a mystery or perhaps no. Some examples are given next, which are well known by the research community and are well documented in literature.

Mercury in rainfall has been controlled during the past 20 years in the USA. Levels have increased in many sites reflecting an increment in the emissions originated from coal-burning power plants (Schure 2016). The most toxic species of mercury, methyl mercury, has been noticed recently as present in the waters of California's coast at levels 17 times higher than normal ones when the elephant seals shed their

Responsible editor: Philippe Garrigues

Carlos Lodeiro

cle@ fct.unl.pt; http://www.bioscopegroup.org

Jose Luis Capelo

jlcm@fct.unl.pt; http://www.ptim2014.com; http://

www.bioscopegroup.org

Elisabete Oliveira

http://www.bioscopegroup.org

Cristina Nuñez

http://www.bioscopegroup.org

1 BIOSCOPE Group, UCIBIO@REQUIMTE, Chemistry Department, Faculty of Science and Technology, University NOVA of Lisbon, 2829-516 Caparica, Portugal

2 ProteoMass Scientific Society, Madan Park. Rúa dos Inventores, 2825-182 Caparica, Portugal

3 Present address: Pharmacology Department, Faculty of Veterinary, University of Santiago de Compostela, 27002 Lugo, Spain outermost layer of skin and hair (Cossabon 2015). Guess where this mercury comes from. Astonished by this? Then you will think twice before eating tuna as methyl mercury levels are increasing at an unbelievable rate of $3.8 \%$ per year just in this fish.

Emerging contaminants (Petrie 2015) are generally defined as any synthetic or naturally occurring chemical or microorganism that becomes considered as contaminant due to their increasing levels in the environment, which ultimately are considered a threat to humans. Rivers, many of them sources of drinking water, are being transformed in pharmaceuticals, literally. Thus, bupropion, carbamazepine, citalopram, fluoxetine, gabapentin, lamotrigine and venlafaxine which are included in the categories of antidepressants, anti-seizure compounds and mood stabilisers were found in the rivers of Minnesota (Writer 2016). Soon, the easiest way to take a coffee will be to drink a glass of water of the nearest river, as caffeine has spread so quickly, at ppb levels in some cases [4]. Even better, pain is going to become a meaningless word, as levels of molecules such as diclophenac in drinking water have grown steadily during the last years (Richardson and Kimura 2016).

Emerging nanomaterials (Gong et al. 2015; Oliveira 2015), cracking problems (Kurtzman 2016), and mining contaminations (Giripunje 2015) are other biggest issues to be resolved.

We, the scientific community, have two main responsibilities with our society. The first one deals with our capability to develop new methodologies to detect and monitor not only well known but also new contaminants. The communities we are living in are expecting from us an effort directed towards making a safer world - our duty. The second one deals with our ability to deliver ways to clean the divine liquid, the water, from the poisons our way of living drain on it slowly but constantly.

As it was written above, we are killing right now the forthcoming generations, and this is not a dramatic fantasy 
originated in the mad mind of a researcher. It is an inconvenient truth, scientifically proven.

The first International Caparica Conference on Pollutant Toxic Ions and Molecules, PTIM2015 was addressed to enrol brilliant minds working in any way within the fields of detecting, controlling, removing or making pollutant toxic ions and molecules. The plenary speakers Joao Crespo (Portugal); Vito Lippolis (Italy); José Gomez-Ariza (Spain); Manuel Miró-Llado (Spain); Julia Ljibimova (USA) as well as the Keynote speakers, Wayne Jones (USA), Graça Neves (Portugal); Andrea Bencini (Italy); Mario Diniz (Portugal); Gerald Zagury (Canada); Jose Santana-Rodríguez (Spain); Irene C Lo (Hong-Kong) and 185 participants shown during the conference their most important results about A Global Pollution Problem: Trends in Detection and Protection.

The collection of papers presented in this special issue is the result of the effort the scientific community is doing for saving the world for the generations to come. We would like to thank all the contributors as well as the editor-in-chief of the Environmental Science and Pollution Research Journal, professor Philippe Garrigues and the Springer editorial team for allowing us to launch this special issue.

Acknowledgments All guest editors thank Proteomass Scientific Society (Portugal) and the Unidade de Ciências Biomoleculares Aplicadas-UCIBIO@REQUIMTE-FCT-UNL (FCT/MEC-UID/Multi/ 04378/2013 and ERDF - PT2020) for the financial support.

\section{References}

Cossabon et al (2015) Mercury offloaded in northern elephant seal hair affects coastal seawater surrounding rookery. PNAS 112(39): 12058-12062. doi:10.1073/pnas. 1506520112

Giripunje et al (2015) Remediation techniques for heavy-metals contamination in lakes: a mini-review. Clean-Soil Air Water 43(9):13501354. doi:10.1002/clen.201400419

Gong et al (2015) Application of iron sulphide particles for groundwater and soil remediation. Water Res 89:309-320. doi:10.1016/j.watres. 2015.11.063

Kurtzman et al (2016) Soil-aquifer phenomena affecting groundwater under vertisols: a review. Hydrol Earth Syst Sci 20(1):1-12. doi: 10.5194/hess-20-1-2016

Oliveira et al (2015) Revisiting the use of gold and silver functionalised nanoparticles as colorimetric and fluorimetric chemosensors for metal ions. Sensors Actuators B Chem 212:297-328. doi:10.1016/ j.snb.2015.02.026

Petrie et al (2015) A review on emerging contaminants in wastewaters and the environment: current knowledge, under studied areas and recommendations for future monitoring. 72 (1):3-27. doi:10.1016/j. watres.2014.08.053

Richardson SD, Kimura SY (2016) Water analysis: emerging contaminants and current issues. Anal Chem 88(1):546-582. doi:10.1021/ acs.analchem.5b04493
Schure et al. Trends in mercury wet deposition and mercury air concentrations across the U.S and Canada. Science of the Total Environment. In Press. doi:10.1016/j.scitotenv.2016.01.061

Writer W et al (2013) Occurrence of neuro-active pharmaceuticals and metabolites in 24 Minnesota rivers and wastewaters. Sci Total Environ 461-462:519-527. doi:10.1016/j.scitotenv.2013.04.099

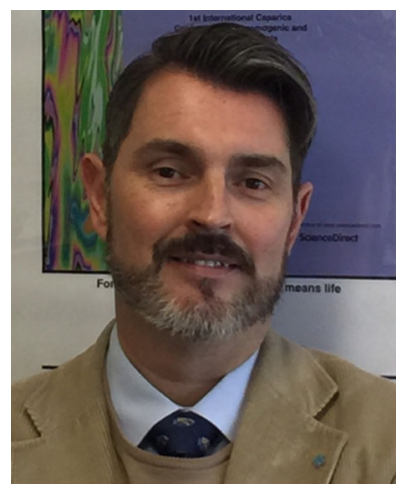

Carlos Lodeiro graduated in Chemistry in 1995 and received his $\mathrm{PhD}$ in chemistry in 1999 by the University of Santiago de Compostela, Spain. In 1999, he moved to the University NOVA of Lisbon (UNL) in Portugal as European Marie Curie postdoctoral researcher in a project concerning molecular devices and machines, and in 2004, he became a fellow researcher and invited assistant lecturer at the REQUIMTE-CQFB, Chemistry Department (UNL). In 2009, Dr. Lodeiro moved to the University of Vigo, Faculty of Sciences of Ourense (FCOU), Spain, as IPP (Isidro Parga Pondal) researcher-lecturer. Since 2012, he is assistant Professor at the Chemistry Department UCIBIOREQUIMTE Laboratory in the Faculty of Science and Technology, University NOVA of Lisbon. Dr. Lodeiro is a Fellow of the Royal Society of Chemistry since 2014 and member of the Portuguese Chemistry Society. Presently, he is a co-head of the BIOSCOPE research group and Co-CEO of the PROTEOMASS Scientific Society. His research interest comprises (i) physical-organic and physical-inorganic chemistry of fluorescence chemosensors, (ii) nanoparticles and applications, (iii) supramolecular analytical proteomics, (iv) onco and nanoproteomics. C. Lodeiro is an author or co-author of close to 200 manuscripts, 1 patent, 15 book chapters and 20 books as co-editor.

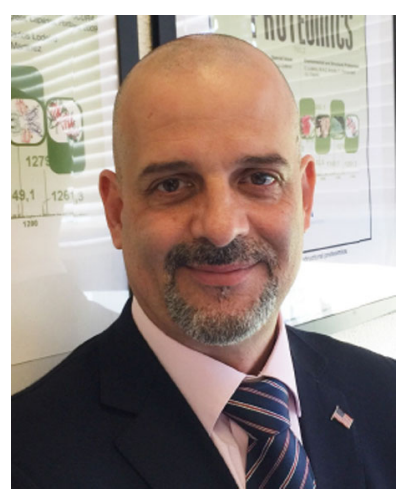

José Luis Capelo received his $\mathrm{PhD}$ in Chemistry in 2002 by the University of Vigo (Spain). In 2002, he moved to the Instituto Superior Técnico de Lisboa (Portugal) as post-doc, and in 2004, he was appointed Fellow Researcher at REQUIMTE, Laboratory associated to the Chemistry Department of the New University of Lisbon. In 2009 , he moved to the University of Vigo at Ourense Campus (Spain), where he works as Fellow Researcher and Lecturer. Since 2012, Dr. Capelo is assistant Professor at the Chemistry Department UCIBIO-REQUIMTE Laboratory in the Faculty of Science and Technology, University NOVA of Lisbon. Dr. Capelo is a Fellow of the Royal Society of Chemistry and member of the Portuguese Chemistry Society. Presently he is a co-head of the BIOSCOPE research group and Co-CEO of the PROTEOMASS Scientific Society. J. L. Capelo has developed research on the following topics: (i) quantification of metal and 
metals species in environmental and food samples, (ii) new methods to speed protein identification mass spectrometry-based workflows, (iii) accurate bottom-up protein quantification, (iv) bacterial identification through mass spectrometry, (v) fast determination of steroids in human samples; (v) biomarker discovery, (vi) application of sensors and chemosensor to the detection/quantification of metals and (vii) nanoproteomics and nanomedicine. J.L Capelo is an author or co-author of more than 170 manuscripts, 2 patents, 12 book chapters and 5 books.

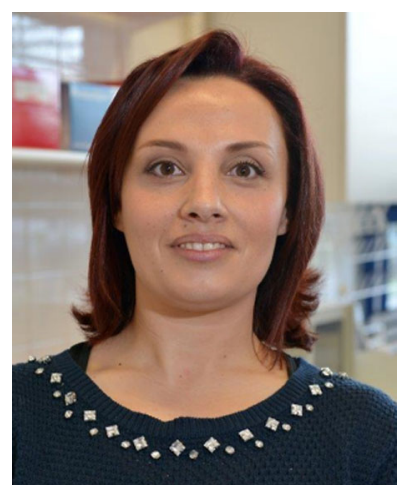

Elisabete Oliveira graduated, in 2006, in Applied Chemistry from FCT-University Nova of Lisbon, Portugal, in 2007 obtained a Master in Biotechnology and completed a $\mathrm{PhD}$ degree in Biotechnology in 2010, at the same university. In 2013, she obtained a second $\mathrm{PhD}$ degree in "Food Science and Technology" by Science Faculty of Ourense Campus in the University of Vigo, Spain. E. Oliveira is an author or co-author of more 55 papers in international peer review journals, 5 book chapters and 3 books. In 2008, E. Oliveira received the prize in Creativity and Quality in Research Activity in sensors area, attributed by Calouste Gulbenkian Foundation, Portugal, and in 2016 the L'Oreal Medal Woman's in Science, Portugal. She spent research periods in national institutions (University of Minho; University of Trás-osMontes and Alto Douro, Portugal) and international institutions (Chemistry department, University of Bologna, Italy and University of Vigo, Spain)
Her scientific interests are focused in (i) synthesis of new bio-inspired emissive peptide as fluorescence chemosensors, (ii) supramolecular chemistry (photophysics and photochemistry), (iii) their multifunctional applications in vitro (solution and solid studies) and in vivo (cell imaging studies) and (iv) synthesis of new emissive nanomaterials, as quantum dots and silica for biomarker discovery in biological samples.

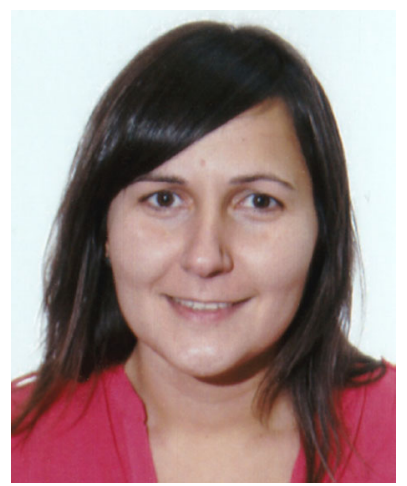

Cristina Núñez obtained her PhD in Chemistry in 2009 by the University of Santiago de Compostela, Spain. She was in short research periods in the University NOVA of Lisbon, REQUIMTE (Portugal) during 2007 and 2008. Between 2010 and 2015 , she performs different post-doctoral research periods in the FCT-REQUIMTE, University NOVA of Lisbon (UNL) in Portugal, and in the Canterbury Christ Church University, UK. Actually, she works as researcher at the Pharmacology Department, Faculty of Veterinary, University of Santiago de Compostela, Lugo Campus, (Spain).

Her research interest comprises the development of novel molecular sensors and the study of their sensing properties in vitro and in vivo. C. Núñez is author or co-author of more than 54 papers in international peer review journals, 13 books and 1 book chapter. 